\title{
Minimal İnvaziv Pektus Ekskavatum Ameliyatı: Tek Merkez Deneyimi
}

\author{
@ (1D) Dr. Öğr. Üyesi Ahmet Acıpayam¹, @ (1D) Dr. Öğr. Üyesi Mahmut Tokur \\ ${ }^{1}$ Kahramanmaraş Sütçü İmam Üniversitesi Tıp Fakültesi Göğüs Cerrahisi Anabilim Dalı, Kahramanmaraş, Türkiye \\ $\ddot{0}$
}

Minimal Invaziv Pektus Ekskavatum Ameliyatı: Tek Merkez Deneyimi

Amaç: Pektus Ekskavatum (PE), en sık görülen göğüs duvarı deformitesidir. PE 300-400 canlı doğumda bir görülür. PE'un cerrahi tedavisinde birçok yöntem bulunmakla birlikte en sık kullanılan yaklașımlar sternum altına metal bir bar yerleștirilerek deformiteyi düzeltmeyi amaçlayan Nuss yöntemidir. Bu çalıșmada kliniğimizde gerçekleștirilen Nuss operasyonlarının sonuçlarını literatür eșliğinde sunmayı amaçladık.

Gereç ve Yöntem: Ağustos 2011-Aralık 2019 tarihleri arasında kliniğimizde PE nedeniyle Nuss operasyonu uygulanan 20 hastanın verileri retrospektif olarak incelendi.

Bulgular: Hastaların 18'i erkek 2'si kadındı. Opere edilen hastaların yaş dağılımı 6 ile 17 yaş arasında olup ortanca yaş 15 idi. Hastalarda operasyon için endikasyon kozmetik sebepler idi. Ortalama hastanede yatış süresi 7 gün (dağılım 3-15 gün) idi. Hastaların \%95’i operasyon sonrası deformitenin düzelmesine bağlı sonuçtan memnun olduğunu ifade ettiler.

Sonuç: PE için yapılan minimal invaziv girișim olan Nuss operasyonu daha kısa operasyon süresi, daha küçük insizyon skarı ve daha estetik görünmesi nedeniyle hasta memnuniyetini arttırmaktadır.

Anahtar Kelimeler: Pektus Ekskavatum, Nuss Operasyonu, Gögüus Deformitesi

\section{Abstract}

\section{Minimally Invasive Pectus Excavatum Surgery: A Single Center Experience}

Objective: Pectus Excavatum (PE) is the most common chest wall deformity. PE is seen once in 300-400 live births. Although there are many methods in the surgical treatment of PE, the most common approach is the Nuss method, which aims to correct the deformity by placing a metal bar under the sternum. In this study, we aimed to present the results of Nuss operations we performed in our clinic in the light of the literature.

Materials and Methods: The data of 20 patients who underwent Nuss operation for PE between August 2011 and December 2019 in our clinic were retrospectively analyzed.

Results: Eighteen of the patients were male and 2 were female. The age distribution of the patients we operated on was between 6 and 17 years and the median age was 15. The indication for the operation in patients was cosmetic reasons. Average length of hospital stay was 7 days (range 3-15 days). 95\% of the patients stated that they were satisfied with the result due to the improvement of the deformity after the operation.

Conclusion: Nuss operation, which is a minimally invasive procedure for PE, increases patient satisfaction due to its shorter operation time, smaller incision scar and more aesthetic appearance.

Keywords: Pectus excavatum, Nuss Operation, Chest Deformity 


\section{Gílis}

Pektus Ekskavatum (PE), en sık görülen göğüs duvarı deformitesidir (1). Halk arasındaki adıyla 'kunduracı göğsü’ olarak bilinen PE 300-400 canlı doğumda bir görülür. Bu deformite sternumun kostal kıkırdaklarla birlikte posterior depresyonu ile karakterize olmakla birlikte bu deformitede manubrium ve ilk iki kosta çoğunlukla normal pozisyonundadır (2). PE'da deformitenin derecesi değişkenlik göstermekle birlikte beyaz ırkta ve erkeklerde daha sık görülür. Asimetrik deformite sık görülür, bazen sternumda rotasyon mevcuttur ve genelde sağ taraf daha çöküktür. Bazı olgularda deformite adölesan çağda gerilese de çoğu zaman daha belirgin hal alır. PE ile birliktelik gösteren en sık anomali skolyozdur ve olguların yaklaşık \%25’inde görülür (3). Azalan sıklıkla konjenital kardiyak anomaliler ve astım, deformiteye eșlik edebilir. Bazı çalıșmalarda ailevi insidans oranı \%40 düzeyine ulaşmaktadır (4). Marfan sendromu ile PE sık birliktelik gösteren bir deformitedir ve skolyoz da bu birlikteliğe eșlik eder (2). Operasyon kararı kozmetik ve psikososyal nedenler sonucunda verilir (5). Modifiye Ravitch ameliyatı klasik düzeltme ameliyatıdır. PE'un cerrahi tedavisinde birçok yöntem bulunmakla birlikte en sık kullanılan yaklașımlar deformite olan kıkırdak kostaların çıkarılmasını ve sternum osteotomisini içeren modifiye Ravitch yöntemi veya sternum altına metal bir bar yerleștirilerek deformiteyi düzeltmeyi amaçlayan Nuss yöntemidir (MIRPE; minimally invasive repair of pectus excavatum). Minimal invaziv olarak yapılan Nuss ameliyatı bu metotlar içerisinde en çok tercih edilen yöntemdir (5). İlk defa 1987 yılında bu yöntem Donald Nuss tarafından gerçekleștirilmiștir (6). Donald Nuss paylaștığı literatürlerde PE düzeltme ameliyatlarının ergenlik öncesi dönemde yapılması önerilmekle birlikte operasyon sonrası \%95 oranında hasta memnuniyeti bildirmektedir (7). Demirkaya ve ark. erkek ve 20 yaş üstü PE deformiteli hastalarda oluşabilecek komplikasyonlara daha dikkatli olunması gerektiğini bildirmișlerdir (8). Cerrahiden kaçınan hafif düzeydeki pektus hastalarında vakum sistemi tedavisinin konservatif amaçlı denemeleri mevcut olup çalıșmalar günümüzde de devam etmektedir. Biz bu makalede genç erişkin yaș grubunda Nuss yöntemi ile yapılan pektus ekskavatum düzeltme ameliyatı deneyimlerimizi literatür eșliğinde paylaşmayı amaçladık.

\section{GEREÇ VE YÖNTEM}

Çalıșma, 01 Ağustos 2011 ile 31 Aralık 2019 tarihleri arasında Kahramanmaraș Sütçü İmam (KSÜ) Tıp Fakültesi Gögüus Cerrahisi kliniğinde Nuss yöntemi ile pektus ekskavatum ameliyatı geçiren 20 hasta verileri retrospektif olarak gerçekleștirildi. Nuss operasyonu için endikasyon kozmetik nedenler idi. İşlem öncesi tüm hastalardan, çocuklarda ise ebeveynlerinden aydınlatılmış onam alındı. Hastalara işlem öncesi posterolateral ve lateral grafiler çekilerek deformite- leri değerlendirildi. Ayrıca ișlem öncesi kardiyak ve solunum fonksiyon testleri değerlendirildi ve alerji öyküsü sorgulanarak operasyon hazırlıkları tamamlandı.

\section{İstatistik Yöntem}

Verilerin istatistiksel analizi IBM SPSS Statistics v25 yazılımı

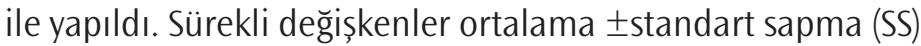
ile gösterildi. Kategorik değișiklikler tanımlayıc istatistiksel yöntemler (frekans ve yüzde) kullanılarak analiz edildi.

\section{Cerrahi Teknik}

Ișlem ameliyathanede sırtüstü pozisyonda, genel anestezi altında çift lümenli endotrakeal tüp takılarak yapıldı. Çöküklüğün bașlangıç ve bitiș noktası ve en derin yeri tespit edilerek uygun bar ölçüsü belirlendi ve bara șekil verildi. Sağ ve sol ön aksiller hatta 2 ve $3 \mathrm{~cm}$ 'lik insizyon ile girilerek pektoral kasların altından tünel açıldı. Sağ videotorakoskopi yardımı ile kılavuz pens retrosternal alandan geçirilerek sol insizyon hattına ulașıldı. Naylon teyp kılavuza bağlandı ve retrosternal tünel içerisinden karșı hemitoraksa geçirildi. Naylon teyp yardımı ile bar sol hemitoraksa geçirildikten sonra barın konveks yüzü inferiora bakacak șekilde çevrilerek deformite düzeltildi. İșlem sonrası ağrı yönetiminde morfin + bupivacain kombinasyonu epidural kateter ile bașlanıp sonrasında bupivacain ile 2-3 gün devam edildi. Epidural kateter yok ise hastaya kontrollü analjezi (PCA) bașlandı. 3-4 gün devam edilerek daha sonra parasetamol $1000 \mathrm{mg} 4 \times 1$, ibuprofen 400 mg 3x1 ile oral ağrı tedavisi bașlandı. Dördüncü beșinci günde tamamen oral antibiyotik ve ağrı kesici tedaviye geçilerek hasta taburcu edildi.

\section{Tablo 1. Olgularm demografik özellikleri}

\begin{tabular}{|l|c|c|}
\hline & Sayı (n) & Yüzde (\%) \\
\hline Cinsiyet & & \\
\hline Erkek & 18 & 90 \\
\hline Kadın & 2 & 10 \\
\hline Semptom & & \\
\hline Göğüs A Ğ̆ısı & 3 & 15 \\
\hline Nefes Darlığı & 2 & 10 \\
\hline Çarpıntı & 1 & 5 \\
\hline Endikasyon & & \\
\hline Göğüis Ağ̆ısı & 3 & 15 \\
\hline Nefes Darlığı & 2 & 10 \\
\hline Çarpıntı & 1 & 5 \\
\hline Endikasyon & & \\
\hline Kozmetik & 20 & 100 \\
\hline
\end{tabular}




\section{BULGULAR}

Pektus deformitesi tanısıyla opere edilen 18'i erkek 2'si kadın 20 hastanın en düșük yașı 6 , en yüksek yașı 18 idi (Tablo 1). Hastaların ameliyat endikasyonlarını kozmetik sebepler olușturmakta idi. PE deformitesi nedeniyle opere edilen hastalarda postoperatif 4 olguda (\%20) pnömotoraks geliști (Tablo 2). Ancak bu olgularda pnömotoraks tüp torakostomi müdahalesine ihtiyaç duymadan spontan geriledi. Postoperatif takiplerde 2 hastada (\%10) yara yeri enfeksiyonu geliști. Günlük pansuman ve uygun antibiyoterapi tedavisi ile enfeksiyon kontrol altına alındı. 1 hastada operasyondan 3 yıl sonra barın sol toraksa giriș yerinde ağrı ve șișlik şikayetinin olması üzerine implantın çıkarılmasına karar verildi. İmplant çıkarılarak șișlik olan bölge debride edildi. Cııarılan implant kültüre gönderildi ancak üreme olmadı. Hastanede yatış süresi 3 ile 15 gün arasında, ortalama yatıș süresi 7 gün olarak hesaplandı. Hastalara taburcu edilirken 2 gün sonra duş olabileceği, 4 hafta fiziksel zorlanmalardan kaçınması, ilk 2 ay 2 kg'dan fazla kaldırmaması ve ilk 3 ay temaslı sporlardan kaçınılması, 6. aydan sonra tüm sporlar serbest olduğu söylenerek önerilerle taburcu edildi. Hastalara taburculuk sonrası ilk ay içerisinde kas iskelet sisteminin gelișmesi için yürüme egzersizi yapması vurgulandı. Hastaların \%95’i operasyon sonrası deformitenin düzelmesine bağlı sonuçtan memnun olduğunu ifade ettiler.

Tablo 2. Komplikasyonlar

\begin{tabular}{|l|c|c|}
\hline & Sayı (n) & Yüzde (\%) \\
\hline Pnömotoraks & 4 & $(\% 20)$ \\
\hline Yara Yeri Enfeksiyonu & 2 & $(\% 10)$ \\
\hline Yabancı Cisim Reaksiyonu & 1 & $(\% 5)$ \\
\hline
\end{tabular}

\section{TARTIȘMA}

Tüm konjenital göğüs duvarı deformitelerinin \%90'ını oluşturan PE en sık görülen göğüs duvarı deformitesidir (9). Deformite erkeklerde kadınlardan 4 kat daha sık görülür (10). Bu çalıșmada da hastaların çoğunluğunu erkekler olușturmakta idi. PE'da çoğu hastada semptom gözlenmez iken, semptom mevcudiyetinde ise hastalarda gögüs ağrısı, dispne, egzersiz toleransında azalma, senkop, özgüven ve sosyal ilișkilerde azalma görülebilmektedir (11). Literatür ile uyumlu olarak bu çalıșmada da hastaların \%70'inde herhangi bir semptom yok iken, 3 hastada göğüs ağrısı ve 2 hastada dispne mevcut idi.

PE'da cerrahi endikasyonlar fonksiyonel nedenler (pulmoner, kardiyak ve ortopedik) ile kozmetik ve psikososyal endikasyonlar olmak üzere iki ana başıı altında incelenebilir. Sternumun kalp ve akciğere olan basısını engellemek, postürü düzeltmek, toraksın normal gelișimine izin vermek ve psikolojik ve emosyonel durumu iyileştirmek pektus cerrahi- sinin temel amaçlarıdır. En sık cerrahi endikasyon psikolojik nedenler ve kozmetik sorunlardır. $(12,13)$. Sıklıkla kozmetik nedenler hastaların yakınmalarında ön planda olsa da nadiren kardiyolojik ve pulmoner fizyolojide değișiklikler olarak semptomatik olan hastalarda mevcuttur. Hastalarda egzersiz ile bașlayan nefes darlığı, eforlu ișlerde yașıtlarına göre geri kalma șeklinde karşımıza çıkabilmektedir $(14,15)$. Bu çalışmadaki tüm hastalarda ameliyat endikasyonunu kozmetik nedenler oluşturmaktaydı.

Pektus ekskavatum onarımında düzeltmenin uygun zamanda yapılması çok önemlidir. Tam olarak net olmamakla birlikte çalışmalarda erișkin yaştaki hasta grubundaki komplikasyonların daha fazla ortaya çıktığı bildirilmiștir (16). PE düzeltme ameliyatının zamanlaması ile ilgili olarak ergenlik öncesi dönemde yapılması önerilmektedir. Ergenlik öncesi dönemde gögüs kafesinin daha iyi şekil alabildiği, iyileșmenin normalden daha hızlı olduğu ve nüks oranının daha az sıklıkla olduğu düșünülmektedir. Bu çalıșmada hastalardan 6 tanesi ergenlik öncesi bașvuruda bulunduğundan bu dönemde opere edilmiștir. Diğer 14 hasta ise ergenlik dönemi bitiminde bașvurup opere edilmiștir. Hastaların daha çok ergenlik dönemi bitiminde ameliyat olmak istemesi ergenlik ile birlikte deformite düzeyinde azalma ya da deformitenin düzeleceği inancı olduğu düșünülmektedir.

Nüks oranını artırmamak için yerleștirilen destek barının ergenlik gelişimi sırasında çıkarılmaması gerektiği bildirmiștir (7). Nuss yöntemi ile yapılan ameliyatlarda yașın artması ile birlikte yeterli kozmetik sonucun elde edilebilmesi için ikinci destek barı da kullanılabilmektedir. Farklı çalıșmalarda, erişkin gruptaki hastalarda iki veya daha fazla bar kullanım oranı \%19 ile \%37 arasında değișkenlik göstermektedir $(17,18)$. ÇaIıșmadaki tüm hastalarda tek destek barı kullanılmıștır. Nuss yönteminde, ameliyat sonrası dönemde ağrı kontrolü özellikle erişkin olgularda çok önemlidir. Ağrı kontrolü epidural analjezi, narkotik analjezikler ve nonsteroid antiinflamatuvar ile sağlanmaktadır (12). Bu çalıșmada ișlem sonrası ağrı yönetiminde morfin + bupivacain kombinasyonu epidural kateter ile bașlanıp sonrasında bupivacain ile 2-3 gün devam edildi. Epidural kateterin kullanılmadığı hastalarda kontrollü analjezi (PCA) bașlandı. 3-4 gün devam edildikten sonra parasetamol 1000 mg 4x1, ibuprofen 400 mg 3x1 ile oral ağrı tedavisine geçildi.

PE operasyonu sonrası dönemde görülebilecek komplikasyonlar arasında pnömotoraks, hemotoraks plevral efüzyon, yara enfeksiyonu, stabilizör dislokasyonu, perikardit, pnömoni, nikel bar alerjisi ve deformitenin nüksü görülebilen komplikasyonlardır. Operasyon sırasında parankimal dokuların gögüus duvarına yapışık olması durumunda diseksiyon esnasında pulmoner parankimal laserasyon gelișen hastalara tüp torakoskopi uygulamak gerekebilir (11). Nedeni tam 
aydınlatılamamakla beraber nikel alerjisine bağlı olabileceği düșünülen az sayıda hastada perikardit veya plevral efüzyon görülebilmektedir (14). Çalıșmadaki hastalardan 4 tanesinde postoperatif pnömotoraks geliști. Ancak takiplerinde pnömotoraks geriledi ve hiçbir hastamızda tüp torakostomi ihtiyacına gerek duyulmadı. 1 hastada postoperatif 3 yıl sonra șişlik ve ağrı șikâyeti nedeniyle bar çıkarıldı.

PE olan kișilerdeki psikolojik etkiler sosyal yașamda kendini anımsanmayacak șekilde belli ederek etkilemektedir (19). Yapılan çalışmalarda bu oranın \%90'a kadar hastalar üzerine olumsuz bir etkilenme olduğunu belirtmiștir (18). Operasyon ile takılan barın vücutta kalma süresi ortalama 2 yıl olmak ile birlikte her hasta özel bir șekilde izlenmeli ve büyüme durumuna göre değerlendirilmelidir $(20,21)$.

Takılan bar planlanan sürenin sonuna gelindiğinde genel anestezi altında çıkarılır. Operasyon sırasında kardiyak ritim monitörden izlenirken akciğer ekspanse halde tutularak pnömotoraks gelişmesini önlenmeye çalıșlır (7). Bu çalıșmada barların hastada kalma süresi 2 ile 4 yıl arasında değișkenlik gösterdi. Ortalama olarak barın vücutta kalış süresi 3 yıl olarak hesaplandı.

Önen ve ark. yaptıkları araștırmada Nuss yöntemi kullanılarak operasyon yapılan genç hastaların bedensel ve ruhsal durumlarındaki pozitif katkı ilk zamanlarda hissedilen ağrı ve cerrahi yaraya rağmen hayat kalitesini arttırmıștır. Opere olan erișkin hastalardaki memnuniyet oranı \%80 ile \%91 arasında değișmektedir (17). Bizim çalıșmamızda \%95 oranında hasta memnuniyeti elde edildi.

\section{SONUÇ}

Bizim deneyimlerimiz Nuss yönteminin estetik artısı ile birlikte ameliyat süresinin diğer cerrahi ișlemlere göre daha kısa olması ve hastalardaki memnuniyet oranının yüksek olması nedeniyle bu yöntemin diğer invaziv girișimlere göre daha tercih edilebilir bir yöntem olduğunu düșünmekteyiz.

\section{BILDIRIMLER}

Değerlendirme

Dıș danıșmanlık

Çıkar Çatıșması

Yazarlar bu makale ile ilgili herhangi bir çıkar çatıșması bildirmemișlerdir.

Finansal Destek

Yazarlar bu makale ile ilgili herhangi bir malî destek kullanımı bildirmemișlerdir.

\section{Etik Beyan}

Bu çalıșma için Kahramanmaraș Sütçü İmam Üniversitesi Klinik Araştırmalar Etik Kurulundan 06.03.2019 tarih ve 019/04 oturum no, 21 karar sayılı yazı ile izin alınmış olup Helsinki Bildirgesi kriterleri göz önünde bulundurulmuştur.

\section{KAYNAKLAR}

1. Huddleston CB. Pectus excavatum. Semin Thorac Cardiovasc Surg 2004;16:225-32. https://doi.org/10.1053/j. semtcvs.2004.08.003

2. Schamberger RC. Chest wall deformities. In Shields TW, Locicero III J, Reed CE, FeinsRH, eds. General Thoracic Surgery, 7th ed. Philadelphia: Lippincott Williams \&Wilkins. 2009:599.

3. Waters PM, Welch K, Micheli LJ, Shamberger R, Hall JE. Scoliosis in children with pectus excavatum and pectus arinatum. J Pediatr Orthop 1989;9:551-6. https://doi. org/10.1097/01241398-198909010-00009

4. Shamberger RC, Welch KJ. Surgical Repair of Pectus Excavatum. J Pediatr Surg 1988;23:615-22. https://doi.org/10.1016/S00223468(88)80629-8

5. Bostancı K, Yüksel M. Minimal invaziv pektus ekskavatum düzeltme ameliyatı: teknik ve uygulama, marmara deneyimi. Toraks Cerrahisi Bülteni 2011;2:196-203. https://doi. org/10.5152/tcb.2011.30

6. Nuss D, Kelly RE Jr, Croitoru DP, Katz ME. A 10-year review of a minimally invasiv etechnique for the correction of pectus excavatum. J Pediatr Surg 1998;33:545-52. https://doi. org/10.1016/S0022-3468(98)90314-1

7. Nuss D. Minimally invasiv e surgical repair of pectusexcavatum. Semin Pediatr Surg 2008;17:209-17. https://doi.org/10.1053/j. sempedsurg.2008.03.003

8. Demirkaya A, Șimșek F, Erşen E, Aksoy B, Sayılgan C, Turna A ve ark. Pektus eskavatumun minimal invazif olarak düzeltilmesinde komplikasyonları belirleyen faktörler. Turk Gogus Kalp Dama 2011;19:201-6. https://doi.org/10.5606/ tgkdc.dergisi.2011.013

9. Blanco FC, Elliott ST, Sandler AD. Management of Congenital Chest Wall Deformities. Semin Plast Surg 2011; 25: 107-16. https://doi.org/10.1055/s-0031-1275177

10. Tokur M, Demiröz ȘM, Sayan M, Tokur N, Arpağ H. Chest wall deformities and coincidence of additional anomalies, screening results of the 25.000 Turkish children with the review of the literature. Curr Thorac Surg. 2016; 1(1): 021-027 https://doi.org/10.26663/cts.2016.0005

11. Chung CS, Myrianthopoulos NC. Factors affecting risks of congenital malformations. I.Analysis of epidemiologic factors in congenital malformations. Report from the Collaborative Perinatal Project. Birth Defects Orig Artic Ser 1975; 11: 1-22.

12. Nuss D, Kelly RE. Indication sand technique of nuss procedure for pectus excavatum. Thoracic Surgery Clinics 2010;20: 58397. https://doi.org/10.1016/j.thorsurg.2010.07.002

13. Özalper MH, Yüksel M. Göğüs duvarı deformiteleri. Turkiye Klinikleri J Thor Surg- Special Topics 2011; 4(2): 130-3.

14. Tokur M. Poland syndrome accompanied by isolated dextrocardia and scoliosis: a case report. Turkish Journal of 
Thoracic and Cardiovascular Surgery 2013:21(1):201-203. https://doi.org/10.5606/tgkdc.dergisi.2013.3928

15. Sigalet DL, Montgomery M, Harder J, Wong V, Kravarusic D, Alassiri A. Long term cardio pulmonary effects of close drepair of pectus excavatum. Pediatr Surg Int 2007; 23:493-7. https:// doi.org/10.1007/s00383-006-1861-y

16. Bawazir OA, Montgomery M, Harder J, Sigalet DL. Mid term evaluation of cardio pulmonary effects of close drepair for pectus excavatum. J Pediatr Surg 2005; 40: 863-7. https://doi. org/10.1016/j.jpedsurg.2005.02.002

17. Pawlak K, Gasiorowski Ł, Gabryel P, Gałecki B, Zielinski P, Dyszkiewicz W. Early and late results of the Nuss procedure in surgical treatment of pectus excavatum in different age groups. Ann Thorac Surg 2016; 102: 1711-6. https://doi. org/10.1016/j.athoracsur.2016.04.098

18. Hanna WC, Ko MA, Blitz M, Shargall Y, Compeau
CG.Thoracoscopic Nuss procedure for young adults with pectus excavatum: excellent midterm results and patient satisfaction. AnnThoracSurg 2013;96:1033-6. https://doi. org/10.1016/j.athoracsur.2013.04.093

19. Yıldızhan A, Candaş FH, Yavuz Ö, Görür R, Ișıtmangil T. Our Nuss procedure experiences in young adult patients with pectus excavatum. Turkish Journal of ThoracicandCardiovascular Surgery. 2015;23(3):519-23. https://doi.org/10.5606/tgkdc. dergisi.2015.10497

20. Pilegaard HK, LichtPB. Routineuse of minimallyinvasivesurgery for pectus excavatum in adults. Ann Thorac Surg 2008;86:9526. https://doi.org/10.1016/j.athoracsur.2008.04.078

21. Abramson H, Abramson L. Minimally access repair of pectus carinatum. In: Saxena AK, editor. Chest wall deformities. Berlin Heidelberg: Springer-Verlag; 2017:545-69. https://doi. org/10.1007/978-3-662-53088-7_47 